\title{
Placebo Use in the United Kingdom: Results from a National Survey of Primary Care Practitioners
}

\author{
Jeremy Howick ${ }^{1 *}$, Felicity L. Bishop ${ }^{2}$, Carl Heneghan ${ }^{1}$, Jane Wolstenholme ${ }^{3}$, Sarah Stevens ${ }^{1}$, \\ F. D. Richard Hobbs ${ }^{1}$, George Lewith ${ }^{4}$
}

1 Department of Primary Care Health Sciences, University of Oxford, Oxford, United Kingdom, 2 Centre for Applications of Health Psychology, Faculty of Social and Human Sciences, University of Southampton, Southampton, United Kingdom, 3 Health Economics Research Centre, Department of Public Health, University of Oxford, Old Road Campus, Headington, Oxford, United Kingdom, 4 Primary Care and Population Sciences, Faculty of Medicine, University of Southampton, Aldermoor Health Centre, Southampton, United Kingdom

\begin{abstract}
Objectives: Surveys in various countries suggest $17 \%$ to $80 \%$ of doctors prescribe 'placebos' in routine practice, but prevalence of placebo use in UK primary care is unknown.

Methods: We administered a web-based questionnaire to a representative sample of UK general practitioners. Following surveys conducted in other countries we divided placebos into 'pure' and 'impure'. 'Impure' placebos are interventions with clear efficacy for certain conditions but are prescribed for ailments where their efficacy is unknown, such as antibiotics for suspected viral infections. 'Pure' placebos are interventions such as sugar pills or saline injections without direct pharmacologically active ingredients for the condition being treated. We initiated the survey in April 2012. Two reminders were sent and electronic data collection closed after 4 weeks.

Results: We surveyed 1715 general practitioners and 783 (46\%) completed our questionnaire. Our respondents were similar to those of all registered UK doctors suggesting our results are generalizable. $12 \%(95 \% \mathrm{Cl} 10$ to 15$)$ of respondents used pure placebos while $97 \%$ (95\% Cl 96 to 98 ) used impure placebos at least once in their career. $1 \%$ of respondents used pure placebos, and $77 \%$ ( $95 \% \mathrm{Cl} 74$ to 79$)$ used impure placebos at least once per week. Most (66\% for pure, $84 \%$ for impure) respondents stated placebos were ethical in some circumstances.

Conclusion and implications: Placebo use is common in primary care but questions remain about their benefits, harms, costs, and whether they can be delivered ethically. Further research is required to investigate ethically acceptable and costeffective placebo interventions.
\end{abstract}

Citation: Howick J, Bishop FL, Heneghan C, Wolstenholme J, Stevens S, et al. (2013) Placebo Use in the United Kingdom: Results from a National Survey of Primary Care Practitioners. PLoS ONE 8(3): e58247. doi:10.1371/journal.pone.0058247

Editor: Laxmaiah Manchikanti, University of Louisville, United States of America

Received September 28, 2012; Accepted February 5, 2013; Published March 20, 2013

Copyright: (C) 2013 Howick et al. This is an open-access article distributed under the terms of the Creative Commons Attribution License, which permits unrestricted use, distribution, and reproduction in any medium, provided the original author and source are credited.

Funding: Jeremy Howick is an NSPCR-NIHR Fellow. The University of Oxford Department of Primary Care Health Sciences and The Southampton Complementary Medical Research Trust (Registered Charity No: 1094802) funded part of the research. No additional external funding was received for this study. The funders had no role in study design, data collection and analysis, decision to publish, or preparation of the manuscript.

Competing Interests: The authors have declared that no competing interests exist.

* E-mail: Jeremy.howick@phc.ox.ac.uk

\section{Introduction}

Surveys in various countries suggest $17 \%$ to $80 \%$ of doctors have prescribed 'placebos' in routine clinical practice, $[1,2,3,4,5,6,7,8,9,10,11,12]$ yet placebo use outside the context of a clinical trial with full informed consent is generally considered unethical. $[13,14,15,16]$ The only survey of placebo use in the UK was a 1976 qualitative study restricted to Welsh practitioners. [2] Hence current prevalence of placebo use in UK primary care is unknown.

A barrier to investigating placebo use is that confusion surrounds the 'placebo' concept. [17,18,19,20,21,22] For example, placebos are often characterized as inactive and nonspecific when in fact they can be active, and have specific effects, especially for relieving pain. $[23,24,25,26,27]$ Since this was an empirical rather than conceptual study we adopted a pragmatic approach and asked doctors whether they used various treatments described as placebos in other similar surveys. Our approach has the advantage of being useful: patients, doctors, and policy makers care more about whether particular treatments are effective and ethical than whether these treatments carry the label 'placebo'.

We aimed to discover if UK general practitioners (GPs) prescribe placebos as frequently as elsewhere and also to understand the conditions under which general practitioners find placebos ethical. [13,14] Ethical placebos may have a role in health care, for example in treating patients with chronic osteoarthritic pain, where current best practice often involves medications such as non-steroidal anti-inflammatory drugs (NSAIDs) that have known harmful side effects. [28,29,30]Our aim was not to study placebo use within the context of controlled trials. 


\section{Methods}

\section{Participants}

Participants in this cross-sectional survey were randomly sampled from among the UK general practitioners registered with a clinician marketing service (Doctors.net); 71\% of UK GPs are registered with the service. Ethical approval was obtained from the University of Oxford, and the survey was sent via email on 26 April 2012. Email reminders were sent out on 30 April and 4 May, and the survey closed on 21 May 2012.

We required 655 responses for our sample to reflect the population with $99 \%$ confidence $( \pm 5 \%)$. Based on recent surveys, $[4,11]$ we predicted a response rate of between 40 to $60 \%$ and emailed the survey to 1,715 general practitioners.

\section{Defining pure and impure placebos}

Following other recent surveys we adopted the convention of dividing placebos into 'pure' and 'impure'. [4,7,10,11,12] Pure placebos are interventions such as sugar pills (which are available commercially [31]) or saline injections without direct pharmacologically active ingredients for the condition being treated. Impure placebos are substances, interventions or 'therapeutic' methods which have known pharmacological, clinical or physical value for some ailments but lack specific therapeutic effects or value for the condition for which they have been prescribed. These may include:

- Positive suggestions

- Nutritional supplements for conditions unlikely to benefit from this therapy (such as vitamin $\mathrm{C}$ for cancer)

- Probiotics for diarrhea

- Peppermint pills for pharyngitis

- Antibiotics for suspected viral infections [5]

- Sub-clinical doses of otherwise effective therapies [32]

- Off-label uses of potentially effective therapies

- Complementary and Alternative medicine (CAM) whose effectiveness is not evidence-based [33,34]

- Conventional medicine whose effectiveness is not evidencebased $[35,36,37,38]$

- Diagnostic practices based on the patient's request or to calm the patient such as

- Non-essential physical examinations

- Non-essential technical examinations of the patient (blood tests, X-rays)

\section{Survey instrument}

To compare our results with other surveys of placebo use we adapted recently published questionnaires for a UK audience. $[4,7,9,10,11,12]$ We piloted our questionnaire with GP colleagues at Oxford and Southampton $(n=21)$ to ensure face validity. The questionnaire asked respondents to note how frequently (if at all) they used placebo interventions. Additional items asked about reasons for placebo use, circumstances under which practitioners felt placebo use was ethically acceptable, and what practitioners told patients when they prescribed placebo interventions. To address the risk of social desirability bias in our responses our questionnaire began with two case studies that avoided using the term 'placebo', one about using antibiotics for throat infections and the other about a hospital patient who responded when the intravenous painkillers were replaced by saline injection. To minimize conceptual ambiguity we included our definitions of pure and impure placebos on the first and subsequent pages of the questionnaire, and respondents were offered the option to answer that a given intervention was not a placebo. Our questionnaire included open-ended questions where respondents could provide comments about their definitions of placebos.

\section{Statistical analysis}

Participants entered their responses directly into an online survey using Confirmit. [39] We used descriptive statistics (means and $95 \%$ confidence intervals) to describe practitioner characteristics and frequencies of placebo use. We reported how often respondents used all pure and all impure placebos at least once in their career (mean and 95\% CI). For each type of placebo we categorized prevalence of use into: frequent (daily or approximately once per week), occasional (approximately once per month or once per year) and rare/never (more than once per year or never). We also noted reasons for prescribing placebos (mean and 95\% CI), and attitudes towards the ethics of placebos. We analyzed differences (RR and 95\% CI) between usage among respondents who stated placebos were categorically unacceptable in routine practice and those who stated placebos were sometimes acceptable.

We used Fisher's exact test to investigate whether placebo use was associated with gender, year of qualification (stratifying 1989 or earlier/1990-1999/2000 or later), number of patients treated per week (100 or less/101 to $150 / 151$ or more), number of days per week in current practice $(0-3 / 3.5-4.5 / 5$ or more). A Bonferroni correction was used to allow for the 14 types of placebo against which each characteristic (gender, year qualified, etc.) was tested: each test was deemed significant if $\mathrm{p}<0.0036$, giving a 5\% type I error rate across all 14 tests for each characteristic. All analyses were conducted using STATA (version 11).

\section{Results}

\section{Respondent characteristics}

Of the 1715 primary care practitioners sent the questionnaire $783(46 \%)$ responded. There were more male (55\%) respondents, the average year of qualification was 1993 (range 1964 to 2007, mode $=2000$ ), the average days per week in current practice were 4 (range 0.5 to 6 ), and the mean number of patients treated per week was 123 (range 6 to 450). Our participants were similar to those registered with the General Medical Council (GMC): 52\% of UK general practitioners are male, and the mode of UK GP qualification year is 2000. [40,41,42] One respondent reported treating zero patients per week and working clinically zero days per week and we excluded them from the analysis.

\section{Pure placebos: prevalence of use}

$12 \%$ (95\% CI 10 to 15$)$ of respondents reported using pure placebos (sugar pills or saline injections) at least once in their career (see Table 1). 1\% (95\% CI 0 to 2 ) of respondents reported using pure placebos at least once per week (see Table 2).

Reasons for prescribing pure placebos varied. 55\% (95\% CI 51 to 59) of respondents reported prescribing pure placebos to induce possible psychological treatment effects, $33 \%$ (95\% CI 30 to 36$)$ to calm patients, $32 \%(95 \%$ CI 29 to 35$)$ because the patient requested a therapy, and $31 \%(95 \%$ CI 28 to 34$)$ to treat nonspecific complaints. 
Table 1. Summary of placebo usage.

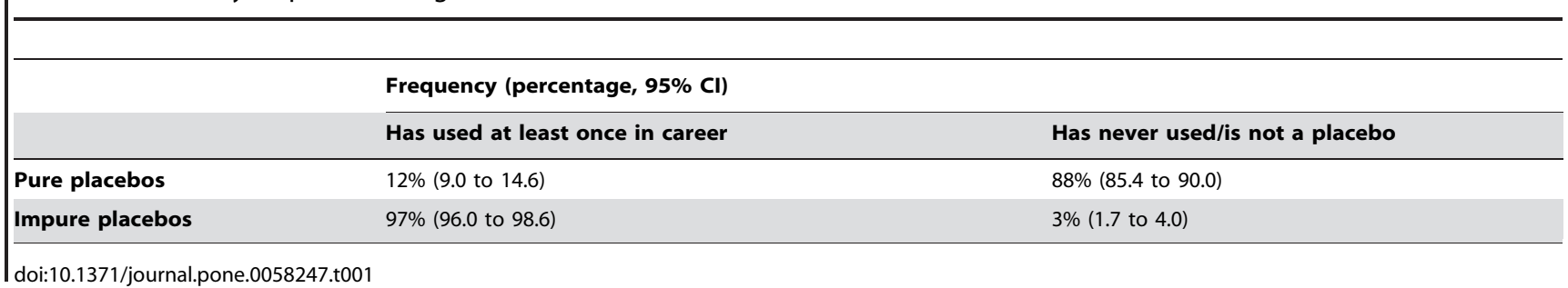

Impure placebos: prevalence of use

$97 \%$ (95\% CI $96 \%$ to 98 ) of respondents reported using impure placebos at least once in their career (see Table 1), and 77\% (95\% CI 74 to 79 ) reported using impure placebos frequently (at least once per week, see Table 2). Several impure placebos were used frequently by at least a quarter of GPs. These included nonessential physical examinations $(54 \%, 95 \%$ CI 50 to 57), positive suggestions $(52 \%, 95 \%$ CI 48 to 55$)$, non-essential technical examinations $(31 \%, 95 \%$ CI 28 to 34$)$, conventional medicine whose effectiveness is not evidence-based (26\%, 95\% CI 23 to 29), and antibiotics for suspected viral infections (25\%, 95\% CI 22 to 28).

Common reasons for prescribing impure placebos were similar to reasons for prescribing pure placebos. 50\% (95\% CI 47 to 54) reported prescribing them for a possible psychological treatment effect, $45 \%$ (95\% CI 42 to 49$)$ because the patient requested a therapy, 35\% (95\% CI 32 to 39) for non-specific complaints, and $32 \%$ (95\% CI 29 to 35$)$ to calm patients.

\section{Pure placebos: ethical attitudes}

$66 \%(95 \%$ CI 63 to 70$)$ of respondents felt there were circumstances in which pure placebos were ethically acceptable (see Table 3). Yet $82 \%$ (95\% CI 79 to 85) stated pure placebos were unacceptable when they involved deception, and 90\% (95\% CI 88 to 92) stated they were unethical when they endangered patient/doctor trust. Half $(53 \%)$ of doctors who prescribed pure placebos told patients that 'this therapy has helped many other patients,' a quarter (25\%) told patients that the treatment promoted self-healing and a tenth $(9 \%)$ told the patient the treatment was a placebo. Doctors who reported finding pure placebos 'never acceptable in clinical practice' were less likely to prescribe them $(6 \%$ versus $15 \%$, relative rate $(\mathrm{RR}) 0.41,95 \%$ CI 0.25 to 0.69 ). Respondents who reported finding pure placebos 'never acceptable' prescribed them for possible psychological treatment effect or to offer treatment to those with untreatable/ incurable disease. Sample sizes were too small to formally analyze reasons for placebo use among doctors who found pure placebos never ethically acceptable.

Table 2. Frequency of placebo use by type of placebo.

\begin{tabular}{|c|c|c|c|c|}
\hline & \multicolumn{3}{|c|}{ Frequency (percentage, 95\% CI) } & \multirow[t]{2}{*}{ This is not a placebo } \\
\hline & $\begin{array}{l}\text { Frequently (daily or } \\
\text { approximately once per } \\
\text { week) }\end{array}$ & $\begin{array}{l}\text { Occasionally (approximately } \\
\text { once per month or at least } \\
\text { once in the last year) }\end{array}$ & $\begin{array}{l}\text { Rare (less than } \\
\text { once per year or } \\
\text { never) }\end{array}$ & \\
\hline PURE PLACEBOS & $0.90 \%(0.2$ to 1.6$)$ & $1.5 \%(0.7$ to 2.4$)$ & $97.4 \%$ (96.3 to 98.5$)$ & $0.3 \%(0.0$ to 0.6$)$ \\
\hline Sugar Pills & $0.5 \%(0$ to 1.0$)$ & $1.0 \%(0.3$ to 1.7$)$ & $97.8 \%$ (96.8 to 98.8$)$ & $0.6 \%(0.1$ to 1.2$)$ \\
\hline Saline injections & $0.4 \%$ (0 to 0.8$)$ & $1.4 \%(0.6$ to 2.2$)$ & $97.6 \%$ (96.5 to 98.6$)$ & $0.6 \%(0.1$ to 1.2$)$ \\
\hline IMPURE PLACEBOS & $77.0 \%(74.0$ to 79.9$)$ & $18.0 \%(15.3$ to 20.7$)$ & $4.6 \%(3.1$ to 6.1$)$ & $0.4 \%(0.0$ to 0.8$)$ \\
\hline Positive suggestions & $51.7 \%(48.2$ to 55.2$)$ & $19.6 \%$ (16.8 to 22.3$)$ & $18.3 \%(15.6$ to 21.0$)$ & $10.5 \%$ (8.3 to 12.6$)$ \\
\hline Nutritional supplements & $5.9 \%(4.2$ to 7.5$)$ & $23.9 \%(20.9$ to 26.9$)$ & $68.8 \%(65.6$ to 72.0$)$ & $1.4 \%(0.6$ to 2.2$)$ \\
\hline Probiotics for diarrhea & $9.0 \%$ (7.0 to 11.0$)$ & $39.0 \%$ (35.6 to 42.4$)$ & $45.5 \%$ (42.0 to 49.0$)$ & $6.5 \%(4.8$ to 8.3$)$ \\
\hline Peppermint pills for pharyngitis & $1.8 \%(0.9$ to 2.7$)$ & $6.5 \%$ (4.8 to 8.3$)$ & $89.8 \%$ (87.6 to 91.9$)$ & $1.9 \%(1.0$ to 2.9$)$ \\
\hline Antibiotics for suspected viral infections & $25.2 \%(22.2$ to 28.2$)$ & $51.2 \%$ (47.6 to 54.7$)$ & $19.7 \%$ (16.9 to 22.5$)$ & $4.0 \%(2.6$ to 5.3$)$ \\
\hline Sub-clinical doses of effective therapies & $4.9 \%$ (3.6 to 6.4$)$ & $34.4 \%$ (31.1 to 37.7$)$ & $57.3 \%$ (53.8 to 60.8 ) & $3.5 \%(2.2$ to 4.7$)$ \\
\hline Off-label uses of a potentially effective therapy & $13.0 \%(10.7$ to 15.4$)$ & $45.4 \%$ (41.9 to 48.9$)$ & $33.6 \%(30.3$ to 36.9$)$ & $7.9 \%(6.0$ to 9.8$)$ \\
\hline $\begin{array}{l}\text { Complementary and Alternative medicine (CAM) } \\
\text { whose effectiveness is not evidence-based }\end{array}$ & $6.8 \%(5.0$ to 8.5$)$ & $44.2 \%(40.8$ to 47.7$)$ & $44.8 \%$ (41.3 to 48.2$)$ & $4.2 \%(2.8$ to 5.6$)$ \\
\hline $\begin{array}{l}\text { Conventional medicine whose effectiveness is not } \\
\text { evidence-based }\end{array}$ & $26.2 \%(23.1$ to 29.3$)$ & $51.2 \%(47.6$ to 54.7$)$ & $16.0 \%(13.4$ to 18.6$)$ & $6.6 \%(4.9$ to 8.4$)$ \\
\hline Non-essential physical examinations & $53.6 \%(50.1$ to 57.1$)$ & $28.6 \%(25.5$ to 31.8$)$ & $12.4 \%(10.1$ to 14.7$)$ & $5.4 \%$ (3.8 to 7.0$)$ \\
\hline $\begin{array}{l}\text { Non-essential technical examinations of the patient } \\
\text { (blood tests, X-rays) }\end{array}$ & $31.2 \%(28.0$ to 34.4$)$ & $50.5 \%(47.0$ to 54.0$)$ & $13.6 \%(11.2$ to 16.0$)$ & $4.7 \%(3.2$ to 6.2$)$ \\
\hline OTHER* & $36.4 \%$ (33.0 to 39.7$)$ & $27.3 \%(24.3$ to 30.4$)$ & $18.2 \%(15.5$ to 20.9$)$ & $18.2 \%(15.5$ to 20.9$)$ \\
\hline
\end{tabular}

${ }^{*} \mathrm{CBT}$, ferrous sulphate, gesture and intonation in addition to positive suggestion, medication, physiotherapy, joint injection, reassurance, referral to website, reassurance, 'tell them my own or my family member with the same problem', unnecessary referrals.

doi:10.1371/journal.pone.0058247.t002 
Table 3. Summary of practitioner beliefs about ethical acceptability of placebo use.

\begin{tabular}{lll}
\hline & & \\
\hline & \multicolumn{1}{l}{ Percentage (95\% CI) of GPs agreeing with statement for } \\
\cline { 2 - 3 } Statement & PURE placebos & IMPURE Placebos \\
\hline Placebos are acceptable when used for their psychological effect & $52.8 \%(49.3$ to 56.3$)$ & $58.3 \%(54.9$ to 61.8$)$ \\
Placebos are acceptable when all other therapies have been exhausted & $49.7 \%(46.2$ to 53.2$)$ & $66.5 \%(63.2$ to 69.8$)$ \\
Placebos are acceptable when the patient wants or expects this therapy & $47.2 \%(43.7$ to 50.7$)$ & $46.7 \%(43.2$ to 50.2$)$ \\
Placebos are acceptable when clinical experience has shown a benefit & $60.7 \%(57.3$ to 64.2$)$ & $79.0 \%(76.2$ to 81.9$)$ \\
Placebos are not acceptable when they involve deception & $82.0 \%(79.3$ to 84.7$)$ & $82.4 \%(79.7$ to 85.0$)$ \\
Placebos are not acceptable when they endanger patient/doctor trust & $90.2 \%(88.1$ to 92.2$)$ & $93.6 \%(91.9$ to 95.3$)$ \\
Placebos are not acceptable because the efficacy is insufficient & $52.8 \%(49.3$ to 56.3$)$ & $35.0 \%(31.7$ to 38.4$)$ \\
Placebos are not acceptable because of legal problems & $61.4 \%(58.0$ to 64.8$)$ & $45.3 \%(41.8$ to 48.8$)$ \\
Placebos are not acceptable because they have possible adverse effects & $41.6 \%(38.1$ to 45.0$)$ & $55.8 \%(52.3$ to 59.2$)$ \\
Placebos are acceptable in some circumstances in clinical practice & $66.2 \%(62.9$ to 69.6$)$ & $84.1 \%(81.6$ to 86.7$)$ \\
Placebos are never acceptable in clinical practice & $32.5 \%(29.2$ to 35.8$)$ & $13.9 \%(11.5$ to 16.4$)$ \\
\hline
\end{tabular}

doi:10.1371/journal.pone.0058247.t003

\section{Impure placebos: ethical attitudes}

84\% (95\% CI 82 to 87) of respondents agreed there were some circumstances in which impure placebos were ethically accepable (see Table 3). Yet $82 \%$ (95\% CI 80 to 85 ) stated impure placebos were unacceptable when they involved deception and 94\% (95\% CI 92 to 95) stated they were unethical when they endangered patient/doctor trust. Of doctors who prescribed impure placebos, half $(48 \%)$ told patients 'this therapy has helped many other patients,' $18 \%$ told patients that the treatment promoted selfhealing, and $8 \%$ told the patient the treatment was a placebo. Three respondents who used the free text option noted saline injections were useful for treating opiate addicts inappropriately presenting to emergency departments. Doctors who reported finding impure placebos 'never acceptable in clinical practice' are also less likely to prescribe them in clinical practice' (91\% versus 99\%, RR 0.92, 95\% CI 0.86 to 0.98). GPs who prescribed impure placebos in spite of finding them 'never acceptable', did so for the following common reasons: to calm the patient, because the patient requested treatment, for possible psychological treatment effect or as a supplement to medication. Sample sizes were too small to formally analyze reasons for placebo use among doctors who never found impure placebo use to be ethically acceptable.

\section{Predictors of placebo use}

There were differences between males and females in the frequency of use of several placebos. More females used positive suggestions on a frequent basis (64\% versus $52 \%$, RR $1.23,95 \%$ CI 1.08 to $1.40, P=0.0013$ ), and more males prescribed off-label uses of potentially effective therapy frequently (18\% versus $10 \%$ RR $1.82,95 \%$ CI 1.23 to $2.71, P=0.0029)$. There was a significant association between the number days per week spent in practice and the frequency of use of non-essential physical exams. $92 \%$ of those working $0-3$ days in practice used non-essential physical exams frequently or occasionally compared to $77 \%$ of those working 5 days or more (RR 1.19, 95\% CI 1.07 to 1.32 , $P=0.0014)$. We suspected females spent fewer days in practice and this might have confounded the association between sex and frequency of non-essential examinations. We repeated Fisher's exact test and found no significant associations between the number of days per week spent in practice and frequency of nonessential physical exam use for males or females $(P=0.142)$.

\section{Discussion}

\section{Summary of main findings}

Placebos may represent one of the more commonly used treatments in UK primary care in spite of (perhaps sometimes unjustified) ethical constraints. Twelve percent of respondents reported using pure placebos, and 97\% reported using impure placebos at least once in their career. Many placebos were used frequently by over half the respondents, and most general practitioners felt there were circumstances in which impure and pure placebos were ethically acceptable. Half of the practitioners who use placebos informed their patients that this intervention has helped other patients without specifically telling them that they were prescribing a placebo. This raises unresolved ethical issues about how GPs approach informed consent in relation to their prescriptions of placebos. The analysis indicates potential gender differences in the frequency of placebo prescriptions.

\section{Strengths and Limitations}

Given ethical constraints surrounding placebo use in clinical practice, general practitioners completing surveys may have understated their use of placebos. The response rate $(46 \%)$ raises questions about representativeness, yet our respondents were similar to GPs registered with the GMC.

Our pragmatic definition of 'placebo', while consistent with other surveys, could be challenged. For example, it might turn out that some conventional therapies that lack an evidence base (considered to be placebos in our survey) are eventually proven to be efficacious non-placebo treatments. In addition the distinction between pure and impure placebos is only useful as a rough guide. Just as antibiotic treatments can function as treatments (for bacterial infections) or placebos (for viral infections), so sugar pills and saline solutions can be treatments for some conditions and placebos for others. For instance sugar is not inert with respect to diabetes. $[18,22,43]$ and saline solution is an effective treatment to treat increased intracranial pressure. [44] The difference between pure and impure placebos is therefore stochastic: pure placebos are less often used as treatments as compared with impure placebos.

We considered that for practical and internationally comparative purposes it is more important to describe treatments often labeled as placebos rather than resolve the philosophical debate 
over the definition of placebos. UK GPs appeared to agree with our definition. $82 \%-99 \%$ (depending on which placebo treatment) agreed that the treatments listed as placebos were, in fact, placebos.

Other limitations include potential recall and response bias. $[45,46]$ Given the ethical strictures against placebo use, these biases may have let to an underestimate of reported placebo usage. [47]

\section{Costs and side-effects}

A full cost analysis of placebo prescriptions is beyond the scope of this work yet our data suggest placebos probably cost the NHS many millions of pounds each year. [48,49] Besides the possible financial burden, placebos can be harmful (in which case they are referred to as 'nocebos' [50,51]). For example impure placebos such as antibiotics can have serious adverse ('nocebo') effects. [52]

\section{Other literature}

The survey instrument was derived from previously published investigations and enables our data to be easily compared with other international studies. A 2009 systematic review of 22 surveys of placebo use in general practice in 12 countries found $17 \%$ to $80 \%$ of practitioners had used 'pure' placebos at least once in their career and between $54 \%$ and $57 \%$ had used impure placebos at least once in their career. [5] The latest survey of placebo use was published after the systematic review and found $45 \%$ of German GPs had used pure placebos and 76\% had used impure placebos in the last year. [12] Hence the results of our UK survey are internationally consistent.

\section{References}

1. Berger JT (1999) Placebo medication use in patient care: a survey of medical interns. The Western journal of medicine 170: 93-96.

2. Comaroff J (1976) A bitter pill to swallow: placebo therapy in general practice. The Sociological review 24: 79-96.

3. de Craen AJ, Kaptchuk TJ, Tijssen JG, Kleijnen J (1999) Placebos and placebo effects in medicine: historical overview. Journal of the Royal Society of Medicine 92: 511-515.

4. Fassler M, Gnadinger M, Rosemann T, Biller-Andorno N (2009) Use of placebo interventions among Swiss primary care providers. BMC health services research 9: 144 .

5. Fassler M, Meissner K, Schneider A, Linde K (2010) Frequency and circumstances of placebo use in clinical practice--a systematic review of empirical studies. BMC medicine 8: 15.

6. Goodwin JS, Goodwin JM, Vogel AV (1979) Knowledge and use of placebos by house officers and nurses. Annals of internal medicine 91: 106-110.

7. Hrobjartsson A, Norup M (2003) The use of placebo interventions in medical practice--a national questionnaire survey of Danish clinicians. Evaluation \& the health professions 26: 153-165

8. Kumar S, Little P, Britten N (2003) Why do general practitioners prescribe antibiotics for sore throat? Grounded theory interview study. BMJ 326: 138.

9. Nitzan U, Lichtenberg P (2004) Questionnaire survey on use of placebo. BMJ 329: 944-946.

10. Sherman R, Hickner J (2008) Academic physicians use placebos in clinical practice and believe in the mind-body connection. Journal of general internal medicine 23: 7-10.

11. Tilburt JC, Emanuel EJ, Kaptchuk TJ, Curlin FA, Miller FG (2008) Prescribing 'placebo treatments': results of national survey of US internists and rheumatologists. BMJ 337: a1938.

12. Meissner K, Hofner L, Fassler M, Linde K (2012) Widespread use of pure and impure placebo interventions by GPs in Germany. Family practice 29: 79-85.

13. Bostick NA, Sade R, Levine MA, Stewart DM, Jr. (2008) Placebo use in clinical practice: report of the American Medical Association Council on Ethical and Judicial Affairs. J Clin Ethics 19: 58-61.

14. Foddy B (2009) A duty to deceive: placebos in clinical practice. The American journal of bioethics: AJOB 9: 4-12.

15. WMA (2008) The Declaration of Helsinki. Ferney-Voltaire: WMA.

16. Howick J (2009) Questioning the Methodologic Superiority of 'Placebo' Over 'Active' Controlled Trials American Journal of Bioethics 9: 34-48.

17. Gotzsche PC (1994) Is there logic in the placebo? Lancet 344: 925-926.

18. Grunbaum A (1986) The placebo concept in medicine and psychiatry. Psychol Med 16: 19-38.

\section{Implications for future research and clinical practice}

Placebos are commonly used in UK primary care. Clinical and health service researchers have spent decades investigating ways to effectively utilize 'active' conventional treatments safely, ethically and intelligently. [53] The time has come to use similar methods to investigate ways to rationalize placebo use. The long term viability of placebo use in clinical practice depends on whether placebo benefits outweigh harms, [54] their cost, and whether patients and practitioners deem their use to be ethically acceptable. Further investigations are warranted to develop ethical and cost-effective placebos.

\section{Ethical approval}

Ethical approval was granted by the University of Oxford.

\section{Data sharing}

The questionnaire, and dataset are available from the corresponding author (jeremy.howick@phc.ox.ac.uk).

\section{Acknowledgments}

We thank all our colleagues who provided feedback on the piloted version of the questionnaire. David Mant provided comments in conversation that influenced the conclusion.

\section{Author Contributions}

Conceived and designed the experiments: JH FB GL SS JW CH. Performed the experiments: JH FB GL SS JW CH. Analyzed the data: JH FB GL SS JW FDRH CH. Contributed reagents/materials/analysis tools: JH FB GL SS JW CH. Wrote the paper: JH FB GL SS JW FDRH CH.

19. Nunn R (2009) It's time to put the placebo out of its misery. BMJ 338: 1015. 20. Moerman DE (2002) Meaning, medicine, and the 'placebo effect'. Cambridge: Cambridge University Press.

21. Shapiro A, Morris LA (1978) The Placebo Effect in Medical and Psychological Therapies. In: Garfield SL, Bergin AE, editors. Handbook of Psychotherapy and Behavioural Change: An Empirical Analysis. New York: John Wiley \& Sons. pp. 369-410.

22. Howick J (2008) Philosophical Issues in Evidence-Based Medicine: Evaluating the Epistemological Role of Double Blinding and Placebo Controls. London: London School of Economics.230 p.

23. Benedetti F (2007) Placebo and endogenous mechanisms of analgesia. Handb Exp Pharmacol: 393-413.

24. Benedetti F, Amanzio M, Baldi S, Casadio C, Cavallo A, et al (1998) The specific effects of prior opioid exposure on placebo analgesia and placebo respiratory depression. Pain 75: 313-319.

25. Benedetti F, Amanzio M, Thoen W (2011) Disruption of opioid-induced placebo responses by activation of cholecystokinin type-2 receptors. Psychopharmacology (Berl) 213: 791-797.

26. Benedetti F, Carlino E, Pollo A (2011) How placebos change the patient's brain. Neuropsychopharmacology 36: 339-354.

27. Benedetti F (2009) Placebo effects: understanding the mechanisms in health and disease. Oxford: Oxford University Press.295 p.

28. Roelofs PD, Deyo RA, Koes BW, Scholten RJ, van Tulder MW (2008) Nonsteroidal anti-inflammatory drugs for low back pain: an updated cochrane review. Spine 33: 1766-1774.

29. Ward KE, Archambault R, Mersfelder TL (2010) Severe adverse skin reactions to nonsteroidal antiinflammatory drugs: A review of the literature. American journal of health-system pharmacy: AJHP: official journal of the American Society of Health-System Pharmacists 67: 206-213.

30. Makris UE, Kohler MJ, Fraenkel L (2010) Adverse effects of topical nonsteroidal antiinflammatory drugs in older adults with osteoarthritis: a systematic literature review. The Journal of rheumatology 37: 1236-1243.

31. Reame NK (2005) The emerging science of hot flash relief: legitimizing the 'obecalp' effect. Menopause 12: 4-7.

32. de Jong V, Raz A (2011) Sub-Therapeutic Doses in the Treatment of Depression: The Implications of Starting Low and Going Slow. The Journal of Mind-Body Regulation 1.

33. Kaptchuk TJ (2002) The placebo effect in alternative medicine: can the performance of a healing ritual have clinical significance? Ann Intern Med 136: 817-825. 
34. Ernst E (2000) The role of complementary and alternative medicine. BMJ 321: 1133-1135.

35. Smith R (1991) Where is the wisdom...? BMJ 303: 798-799.

36. Ellis J, Mulligan I, Rowe J, Sackett DL (1995) Inpatient general medicine is evidence based. A-Team, Nuffield Department of Clinical Medicine. Lancet 346: 407-410.

37. Gill P, Dowell AC, Neal RD, Smith N, Heywood P, et al. (1996) Evidence based general practice: a retrospective study of interventions in one training practice. BMJ 312: 819-821.

38. Imrie R, Ramey DW (2000) The evidence for evidence-based medicine. Complement Ther Med 8: 123-126.

39. Confirmit website. Available: http://www.confirmit.com. Accessed 2013 Feb 7.

40. Heneghan C, Perera R, Mant D, Glasziou P (2007) Hypertension guideline recommendations in general practice: awareness, agreement, adoption, and adherence. The British journal of general practice: the journal of the Royal College of General Practitioners 57: 948-952.

41. Murray E (2007) Using the internet for research: results at a keystroke. The British journal of general practice: the journal of the Royal College of General Practitioners 57: 939-940.

42. GMC (2012) List of Registered Medical Practitioners - statistics. London: GMC.

43. Golomb B (2002) When Are Medication Side Effects Due to the Nocebo Phenomenon? JAMA.

44. Strandvik GF (2009) Hypertonic saline in critical care: a review of the literature and guidelines for use in hypotensive states and raised intracranial pressure. Anaesthesia 64: 990-1003.
45. Coughlin SS (1990) Recall bias in epidemiologic studies. Journal of clinical epidemiology 43: 87-91.

46. Mayr A, Gefeller O, Prokosch HU, Pirkl A, Frohlich A, et al. (2012) Web-based data collection yielded an additional response bias-but had no direct effect on outcome scales. Journal of clinical epidemiology 65: 970-977.

47. Worsley A, Baghurst KI, Leitch DR (1984) Social desirability response bias and dietary inventory responses. Human nutrition Applied nutrition 38: 29-35.

48. Health and Social Care Information Centre Prescribing and Primary Care (2012) Prescription Cost Analysis England 2011. Leeds: Health and Social Care Information Centre Prescribing and Primary Care.

49. Department of Health (2011) 2010-11 reference costs publication. London: NHS

50. Enck P, Benedetti F, Schedlowski M (2008) New insights into the placebo and nocebo responses. Neuron 59: 195-206.

51. Colloca L, Finniss D (2012) Nocebo effects, patient-clinician communication, and therapeutic outcomes. JAMA: the journal of the American Medical Association 307: 567-568.

52. Cunha BA (2001) Antibiotic side effects. The Medical clinics of North America 85: 149-185.

53. Howick J (2011) The Philosophy of Evidence-Based Medicine. Oxford: WileyBlackwell.

54. Hrobjartsson A, Gotzsche PC (2010) Placebo interventions for all clinical conditions. Cochrane database of systematic reviews: CD003974. 